Published in the Australian Journal of Botany 54, p97 - 114. (2006)

\title{
A Functional Methodology for Determining the GW Regime Needed to Maintain Health of Groundwater Dependent Vegetation
}

Derek Eamus $^{1}$, Ray Froend ${ }^{2}$, Grant Hose $^{1}$ and Brad Murray ${ }^{1}$

${ }^{1}$ Institute for Water and Environmental Resource Management

and, Department of Environmental Sciences

University of Technology

Sydney,

PO Box 123

NSW, 2007

Australia

${ }^{2}$ Centre for Ecosystem Management

Edith Cowan University

Joondalup

100 Joondalup Dr

WA 6027

Australia

Corresponding author: email Derek.Eamus@uts.edu.au

Keywords: Groundwater dependant ecosystems 


\subsection{Abstract}

In the past, the phrase "environmental allocations of water" has been taken to mean allocation of water to rivers. However, it is now accepted that groundwater dependent ecosystems are an important feature of Australian landscapes and require an allocation of water to maintain their persistence in the landscape. However, moving from this theoretical realization to the provision and implementation of a field-based management regime is extremely difficult.

The following four fundamental questions are identified as being central to the effective management of groundwater dependent ecosystems:

A) How do we identify GDEs in the field? Put another way, which species or species assemblages or habitats are reliant on a supply of groundwater for their persistence in the landscape?

B) What groundwater regime is required to ensure the persistence of a GDE?

C) How can managers of natural resources (principally water and habitats), with limited time, money and other resources, successfully manage GDEs?

D) What measures of ecosystem function can be monitored to ensure that management is effective?

This paper explicitly addresses these questions and provides a step-by-step theoretical and practical framework for providing answers.

\subsection{Introduction}

If the $19^{\text {th }}$ century was dominated by the acquisition and defense of land (territory) and the $20^{\text {th }}$ century was dominated by the acquisition and control of oil and energy resources, then the $21^{\text {st }}$ century will be dominated by the politics of water. Globally, secure access to potable water has been identified as the key political, humanitarian and military flash point (Anon 2000). However, in addition to the human need for water, it has become increasingly clear that the maintenance of a supply of water for the environment is equally important to human welfare. Environmental water requirements support the obvious economic activities of irrigated crops and pastures but also maintain the oft-overlooked direct and indirect values of a large number of ecosystem services (Eamus et al. 2005). Ecosystem services, or ecosystem goods and services (hereafter the two are deemed to be contained within the phrase ecosystem services (ES)) are those processes and attributes of an ecosystem (or part of an ecosystem) that benefit humans (Costanza et al. 1997). The 
range of ES provided include soil formation, regulation of water flow (surface, sub-surface and groundwater recharge), water purification and a range of other services (Costanza et al. 1997).

When groundwater dependent ecosystems (GDEs) are threatened by insufficient supply of groundwater, all the ES provided by that ecosystem are threatened. As demand for water by humans increase, the utilisation of groundwater reserves increases, especially in arid and semi-arid zones. However, it has become apparent that even in humid and wet-dry tropical climates, including northern Australia, significant ecosystems are dependent on groundwater supply for their continued existence and the unavailability of groundwater will have significant deleterious effects on all GDEs (Murray et al. 2003). Consequently there is a clear need to be able to manage groundwater resources so that environmental requirements remain protected. However, there are four major impediments to the sustainable management of GDEs. These can be stated as four questions, the answers to which are difficult to supply:

A) How do we identify GDEs in the field? Put another way, which species or species assemblages or habitats are reliant on a supply of groundwater for their persistence in the landscape?

B) What groundwater regime is required to ensure the persistence of a GDE?

C) How can managers of natural resources (principally water and habitats), with limited time, money and other resources, successfully manage GDEs?

D) What measures of ecosystem function can be monitored to ensure that management is effective?

The purpose of this paper is to provide a conceptual and methodological framework (see Table 1) which explicitly addresses these questions. In the following sections, we explore the assumptions and information required to tackle these questions. The related question: how to prioritise allocations of limited resources to competing GDEs, is dealt with by Murray et al. (2005).

\subsection{How to identify GDEs}

We propose three simple primary classes of GDEs. These are:

I) aquifer and cave ecosystems, where stygofauna (groundwater inhabiting organisms) reside within the groundwater resource. (for discussion see Humphries 2005). These ecosystems include karstic, fractured rock and alluvial aquifers. We also consider the hyporheic zones in this category because these ecotones often support stygobites (obligate groundwater inhabitants). For further discussion of the hyporheic zone see Boulton (2005) 
II) All ecosystems dependent on the surface expression of groundwater. This therefore includes base-flow rivers and streams, wetlands, estuarine seagrass beds, some floodplains and mound springs.

III) All ecosystems dependent on the sub-surface presence of groundwater, often accessed via the capillary fringe (non-saturated zone above the saturated zone of the water table) when roots penetrate this zone. This class includes terrestrial ecosystems such as River Red Gum (E. camuldulensis) forests on the Murray River basin, and Banksia woodland on the Gnangara mound of Western Australia.

Implicit within classes II and III are the associated faunal, microbial and fungal populations. However, within this review, we focus on consideration of the vegetation components of the ecosystem, for which there tend to be more information.

Application of this simple classification system will assist managers in identifying the appropriate techniques (selecting the correct tool) for identifying the presence, timing and nature of groundwater dependency. This classification differs markedly from earlier attempts (eg SKM 2001). Our approach to this classification a scheme has been to identify ecosystems associated with a common groundwater resource. For instance, category II consists of those ecosystems that utilize groundwater once it is expressed above the land surface, while category III consists of those ecosystems that utilize groundwater prior to its surface expression. Category I ecosystems are simply subterranean aquatic ecosystems. This classification also addresses inherent difficulties in earlier classifications of GDEs. For instance, it is difficult to compare meaningfully a "terrestrial fauna" GDE with a near-shore marine GDE given that they are at vastly different levels of biological organisation.

\subsection{A tool-box for identifying GDEs}

A tool-box contains the methods, approaches and techniques required to tackle a problem. In this section we describe these in relation to the first problem confronting managers - how to identify the presence of a GDE in a landscape. 


\subsubsection{Aquifer and cave ecosystems}

All subterranean waters constitute groundwater dependent ecosystems, even if the biotic component of the ecosystem is limited to a microbial flora. The presence of groundwater can be determined by routine geophysical methods such as electrical resistivity and seismic refraction. After this inferential approach, more detailed analysis to identify the presence of biological organisms will include microbial plating and surveys of macro-invertebrates.

\subsubsection{Ecosystems reliant on surface expressions of groundwater}

Groundwater use may be inferred from positive answers to one or more of the following:

a) does a stream/river continue to flow all year, despite prolonged periods of zero surface flows (ie zero or very low rainfall)?

b) For estuarine systems, does the salinity drop below that of seawater in the absence of surface water inputs (e.g. tributaries or stormwater)?

c) Does the volume flow in a stream/river increase downstream in the absence of inflow from a tributary?

d) Is the level of water in a wetland/swamp maintained during extended dry periods?

e) Is groundwater discharged to the surface for significant periods of time each year or at critical times during the lifetime of the dominant vegetation type? If such a resource is present, evolution will have ensured that some species will be using it.

f) Is the vegetation associated with the surface discharge of groundwater different (in terms of species composition, phenological pattern, leaf area index or vegetation structure) from vegetation close-by but which is not associated (ie, accessing) this groundwater?

g) Is the annual rate of water use by the vegetation significantly larger than annual rainfall at the site and the site is not a run-on site (either sub-surface or surface run-on)?

h) Are plant water relations (especially pre-dawn and mid-day water potentials and transpiration rates) indicative of less water stress (potentials closer to zero; transpiration rate larger) than vegetation located nearby but not accessing the groundwater discharged at the surface? The best time to measure this is during rain-less periods.

i) Is occasional (or habitual) groundwater release at the surface associated with key developmental stages of the vegetation (such as flowering, germination, seedling establishment)? 
Affirmative answers to one or more of these questions support the inference that the system is a GDE. However, this inference does not provide any information about the nature of the dependency (obligate or facultative). Neither does it provide information about the groundwater regime (timing of groundwater availability, volume of availability, location of surface expression, the pressure of the groundwater aquifer required to support the surface discharge of groundwater) needed to support the ecosystem. These issues are discussed in section 4.0

More direct evidence that an ecosystem is using groundwater can be obtained by comparing the stable isotope composition of groundwater, soil water, surface water (where relevant) and vegetation xylem water (Thorburn et al 1993; Zencich et al. 2001). Where there is sufficient variation in isotopic composition among these sources then it is possible to identify the single or the most dominant source of water being used by different species at different times of year (Zencich et al. 2002). Thus the use of stable isotopes can provide information about spatial and temporal variation in groundwater dependency within and between species and ecosystems (O'Grady et al. 2005).

For base-flow systems (that is, rivers and streams showing significant flows during periods of zero surface or lateral flows), measurements of the chlorofluorocarbon, magnesium or radon concentrations of river and groundwater supply can identify and quantify the amount and timing of groundwater inflows into the river (Cook et al. 2003).

\subsubsection{Ecosystems reliant on sub-surface presence of groundwater}

The presence of groundwater dependency of ecosystems reliant on sub-surface presence of groundwater may be inferred from positive answers to one or more of the following questions:

j) Is groundwater or the capillary fringe above the water table present within the rooting depth of any of the vegetation?

k) Does a proportion of the vegetation remain green and physiologically active (principally, transpiring and fixing carbon, although stem diameter growth or leaf growth are also good indicators) during extended dry periods of the year?

1) Within a small region (and thus an area having the same annual rainfall and same temporal pattern of rainfall across its entirety), and in an area not having access to run-on or stream or river water, do some ecosystems show large seasonal changes in leaf area index whilst others do not? 
m) See (e), (f) and (g) above.

n) Are seasonal changes in groundwater depth larger than can be accounted for by the sum of lateral flows and percolation to depth (that is, is vegetation a significant discharge path for groundwater; Cook et al. 1998)? Clearly, if the error terms in the estimation of lateral flow and percolation to depth are of similar magnitude or greater than the rate of vegetation water, this method may not be appropriate.

Stable isotopes can be used for these systems too, as can artificial labelling with tracers, such as lithium or deuterium. When tracers are added to the groundwater, the subsequent uptake into vegetation is usually conclusive proof that access by that vegetation is occurring. However, the presence of a tracer in a shallow rooted species can occur if neighbouring deep rooted species exhibit hydraulic lift and the shallow rooted plants then "harvest" this water (Caldwell et al. 1998).

\subsubsection{What degree of dependency is expressed?}

If a habitat or ecosystem is identified as being a GDE, it is valuable to know the degree of dependency exhibited. Different GDEs can exhibit a range of dependencies, from obligate to facultative (Hatton and Evans 1997). Stygofauna can be assumed to be obligately dependent, as are the flora and fauna of mound springs. Obligately dependency should not be taken to mean that groundwater is required continuously. Dependency can be deemed to be obligate if the groundwater is relied upon only very infrequently (6 months in every 10 - 20 years), or frequently but for short periods of time (1 month in every 12 months). The former can be difficult to show, when long-lived trees are being considered. It is possible that groundwater availability is only required every 20 years, to get the population through the end of a particularly long cycle of belowaverage rainfall or it may have played a crucial role in the establishment of a population or cohort. Consequently the impact of the loss of groundwater may not be apparent for very many years. Recharge of floodplains by groundwater may be required infrequently, to recharge soil stores and to support germination and early establishment. However, the importance of those floodplains is significant. Thus the timing and degree of dependency is important knowledge for landscape managers. At the species level, obligate groundwater use is evident if all instances of a species presence is dependent upon either continuous, seasonal or episodic access to groundwater.

In contrast, facultative dependency occurs when groundwater is used when it is available, but its absence does not cause the loss of this vegetation element from that site (O'Grady et al. 2005). Populations of facultative species may include individuals that access groundwater when at shallow 
depth and individuals that have not accessed groundwater throughout their life, e.g. at higher positions in the landscape (Zencich et al. 2002).

To establish the degree of groundwater dependency is difficult and can take many years. Three approaches serve to highlight this.

o) Determine the degree of dependency by quantifying the proportion of annual water use that is derived from groundwater and then assume that this is a measure of the degree of dependency. When there is a consistent utilisation of groundwater each year, this approach may be applied, but it is costly and takes a minimum of 12 months of field work. It also does not differentiate between an oblige use of groundwater (where its absence will have a severe negative impact) and a facultative use (where its absence won't have a severe effect). Both uses could give the same numeric value, but the management implications of loss of groundwater availability differ. Furthermore, when groundwater use becomes significant only occasionally (for example for the last two years of a 10 y cycle of low rainfall) this approach is unlikely to accurately reflect the degree of dependency unless the period of study is longer than the cycle length.

p) An alternative approach used by Scott et al. (1999) and Shaforth et al. (2000) quantifies the relationship between patterns of change in groundwater availability (for example, depth, rate of decline in depth, and duration of excessive depths of the water table) and vegetation responses. Froend and coworkers in Western Australia have applied this approach to Banksia woodland and wetland vegetation of the Gnangara and Jandakot mounds ( Froend et al 2004), to ascertain the response of phreatophytic vegetation to separation from the groundwater source. This can be achieved through either long-term monitoring of vegetation vigour and composition relative to groundwater regime, or via shorter-term drawdown experiments where the watertable is manipulated to induce seasonal or inter-annual change in plant water source partitioning. The former technique provides a more accurate determination of the degree of dependency at the plant community or population level, however, it requires long periods of study. The latter approach is particularly useful for identifying individual dependency on groundwater.

q) A third, inferential approach to estimating the degree of groundwater dependency is to examine temporal patterns in soil moisture availability, rainfall and vegetation attributes known to be influenced by soil moisture content (for example, leaf area index and vegetation water use). From these patterns, rules about the likely temporal dependency 
(rather than the degree of dependency assessed through a quantitative analyses of groundwater use) are deduced. This approach underpins the work of Cook et al. (1998).

\section{1 .5 \\ What vegetation processes are groundwater dependent?}

The maintenance of ecosystem structure and function (a better aim than that of maintaining ecosystem health simply because they are easier to measure) requires the maintenance of some key ecosystem processes. These include:

- Flowering, seed set and germination;

- Growth and persistence

- Seedling establishment and recruitment to reproductive age;

- Mortality

- Nutrient cycling

These are the foundations of ecosystem services (discussed by de Groot et al (2002) and Murray et al (2005).

In order to establish which of these, and other processes, are most sensitive to changes in groundwater availability, one of several approaches can be applied. The first approach requires an analysis of historical records of vegetation behaviour in relation to observed changes in groundwater availability, (for example, flooding or depth to groundwater). There are few sites in Australia where these data are available, but where they are available, important insights to the groundwater dependent processes have emerged (see below).

In the USA, the response of riparian and floodplain Populus spp (cottonwoods) to changes in hydrologic regime has received extensive study (Rood et al. 2003; Scott et al. 1999; Amlin and Rood 2002). Riparian cottonwoods are dependent on shallow alluvial groundwater that is linked to stream water, especially in semi-arid regions. When this water becomes unavailable riparian cottonwoods show including stomatal closure, reduced transpiration and photosynthesis, reduced predawn and midday water potentials and increased xylem cavitation (Rood et al. 2003). Morphological responses including reduced shoot and root growth, crown die-back and eventually increased mortality (Scott et al. 1999). Shafroth et al. (1998) used a modelling approach to determine locations along eight transects along the Bill Williams River in Arizona and combined historic discharge data with data on successful establishment of 3 native and one exotic species. Total basal area of mature woody vegetation, the maximum annual depth to ground water, and the 
maximum rate of decline of the water-table were the variables that best differentiated between quadrats with or without seedlings, there by establishing the importance of these in determining recruitment of seedlings. Using an experimental approach, Amlin and Rood (2002) showed that the low rates of increase in water table $(<2 \mathrm{~cm}$ per day) promoted root and shoot growth in saplings and seedlings of Populus spp and Salix spp. compared to the zero decline treatment. Increases in water table depth larger than $2 \mathrm{~cm}$ per day tended to reduce growth. Clearly, in the short-term, changes in rates of water use and carbon gain occur as plants become drought stressed and stomatal closure occurs. A stimulation of root growth is commonly observed in response to drought. When the drought is prolonged, reduced shoot growth occurs, along with a reduction in leaf area index (crown die-back) and mortality.

Pettit et al. (2001) compared the relationships between flow regime and riparian vegetation characteristics for two rivers in WA. In the Blackwood River (south Western WA), mean monthly discharge is highly seasonal and predictable. In contrast, the Ord River is very seasonal, reflecting the impact of monsoonal weather patterns. In the dry season, May to October, flows are much reduced, but show little variation between months. These differences in stream hydrology, water depth, duration of flooding and the number of flood events were strongly correlated with population dynamics, floristic composition and vegetation structure.

On the Blackwood River, species richness and cover of shrubs reduced with increased frequency and duration of flooding. Cover of exotic species and annual herbs increased with increased flooding. Importantly, the germination of tree seedlings was not influenced by flood regime but the size class distribution of tree species increased with flooding frequency. On the Ord River, species richness was not influenced by flooding regime but the cover of perennial grasses increased with flooding frequency and shrub cover decreased (Pettit et al. 2001).

Froend and McComb (1994) applied an alternative approach to address the question: which vegetation processes are sensitive to alterations in hydrologic regime? They examined the distribution, productivity and reproduction of two emergent maacrophytes in eight wetland lakes on the Swan Coastal Plain (SCP) in WA along a water regime gradient. They showed that standing biomass and ramet and inflorescence densities varied along the gradient, with maximum values occurring most often at intermediate water depths. There was a shift in phenology (ramet emergence, new leaf growth, flowering and seed production) with increasing mean water depth and nutrient status. In addition, seasonal values of above-ground productivity changed along the water regime gradient for both species. Clearly such a comparative approach can be applied in the 
absence of historical data to predict the response of plant communities and populations to altered groundwater availability.

For floodplains and wetlands, long-term records of frequency of flooding and depth of flooding have been linked to population demography and zonataion responses of vegetation (Hughes and Rood 2003). Floodplain forests are dependent on flooding and rely on well-timed, periodic floods for the provision of regeneration sites. They require a tapered flood recession for the successful establishment of seedlings. Such overbank flood events are central to forest regeneration and need only occur infrequently. In contrast, following the establishment of immature forest trees, growth of these trees also requires adequate and variable "maintenance flows" throughout the year. Regeneration flows are often synonymous with flood flows and only occur. Therefore, the hydrologic regime required for recruitment differs from that required to maintain growth from establishment to maturity. Kingsford (2000) similarly examines long-term consequences to vegetation of changes in river flow following regulation (daming) of rivers.

\subsection{What attributes of a groundwater regime are important to a GDE?}

Having established the presence of a groundwater dependency at a site, it is important then to establish which attributes of the groundwater regime are important. Generally, five attributes are important ecologically and these are:

- Level, or depth below the surface, of an unconfined aquifer;

- Groundwater flow rate to the site;

- The pressure within a confined aquifer, which determines the flow of groundwater, to a point of discharge (such as an artesian spring);

- The quality (especially the salt or nutrient or pollutant concentration) of the groundwater;

- Location. Changes in the location of discharge will obviously influence the distribution of the vegetation associated with that discharge.

The location of the discharge is also relatively easy to determine and predicting vegetation response to a change of location of discharge can be relatively simple to predict (although the time-frame may not be). In contrast, ascertaining which of the other attributes is most important may require expert review by hydrologists, ecologists and ecotoxicologists who can determine potentiometric surfaces, flow patterns and aquifer permeability and yield characteristics and water quality needs before any attempt at predicting how vegetation may respond to changes in level or flow rate of 
pressure. It is important to know which attribute is most important at each site as this can be used as a management target and for design of a monitoring system for managers.

To determine the fourth and fifth point is relative simple; analyses of groundwater quality can be routinely undertaken by analytical labs. Generally, poor quality groundwater (high in salt or heavy metals, for example) is less supportive of vegetation. Reduced growth rates, crown die-back, increased mortality and changes in species composition (from less saline tolerant to more saline tolerant species, for example) are impacts of poor quality groundwater. Similarly

To provide managers with empirical targets for management, Loomes (2000) analysed the distribution of 60 wetland species in relation to data on surface water depth, duration and timing of flooding of SCP wetlands. From this analysis she was able to determine the ecohydrological range or average minimum and maximum depths required to maintain viable populations of various wetland species, thereby providing the management goal. Similarly, Froend and Zencich (2001) examined phreatophytic vegetation on the Gnangara mound in WA and identified a range of depths of groundwater that resulted in a range of impacts for different species. Froend and co-workers have identified categories of groundwater useage, depending on groundwater depth. The greater the depth to groundwater, the lower the requirement for groundwater and the more tolerant vegetation is to water table decline due to the corresponding increase in alternative water sources. These alternative sources are primarily the larger volume of unsaturated zone (with increasing depth) exploitable by the plant's root system. Currently, quantitative information suggests reduced importance of groundwater to vegetation existing at depths to groundwater of $>10 \mathrm{~m}$. However, it is assumed that at depths of 10-20 m there is a probability of vegetation groundwater use, although it is thought to be negligible in terms of total plant water use, and that at depths of $20+\mathrm{m}$ this probability is substantially lower (Froend and Zencich 2001).

From the above discussion, it appears that depth to groundwater is often the most important attribute at sites relying on sub-surface provision of groundwater, while it is depth of inundation and frequency of inundation that appears most important to ecosystems relying on both surface expressions of groundwater and overland flow of surface waters (floodplains, wetlands, base-flow rivers). However, pressure is an important attribute too. In the past $50 \mathrm{y}$ the number of free-flowing artesian springs has declined at some locations because of the decline in pressure in the confined aquifer resulting from high rates of extraction. Pressure and flux are also critical for aquifer and cave ecosystems to maintain a supply of organic matter and oxygen throughout the aquifer. Clearly however, water quality is a key issue across all GDEs and is of critical concern given the increasing 
levels of groundwater contamination globally (Danielopol et al 2003). Management strategies for maintaining ecosystem structure and function for these different attributes are likely to differ.

\subsection{What are the safe limits to changes in GW regime?}

Information gained during the determination of which ecosystem process is groundwater dependent (section 3.1.4 above), plus the information gained during determination of which attribute of groundwater is most important to the GDE (section 4.0 above) will also yield information about the range of change in groundwater attributes that can be accepted by the ecosystem. Implicit in this, of course, is that "acceptable change" has been defined by stakeholders (managers, the public, scientists, land owners etc). This is discussed in Murray et al. (2005). Also implicit in the question, "what are safe limits to change?" is the requirement to be able to measure change in ecosystem attributes in a way that allows a monitoring of change through time. This is discussed in section 6.0.

In a minority of cases, safe limits can be relatively easy to ascertain. When the relationship between aquifer pressure and flow in a confined aquifer is known, it might be relatively easy to ensure that the pressure is maintained to ensure a minimum flow rate for conservation of mound springs. Presumably, flow rates into base flow streams can be similarly predicted as a function of pressure gradients. This is the underlying philosophy behind the prevention of groundwater pumping too close (within $3 \mathrm{~km}$ ) to such rivers in the Northern Territory. Similarly, groundwater levels adjacent to rivers must be maintained at depths that exceed river level for the dry season in order to maintain availability for riparian vegetation that uses groundwater in the dry season (Erskine et al. 2003 (this is the NT government Daly River report: Recommended environmental water requirements for the Daly River, NT, based on ecological, hydrological and biological principles; OSS report 175; www.deh.gov.au/ssd/publications/ssr/pubs/ssr175-daly-env-flows.pdf). Erskine et al. (2003) summarise a wealth of data derived from several 3 year studies to determine the environmental water requirements of flora and fauna of the Daly River in the NT. Most importantly, this report provide explicit management targets for minimum dry season river flow rates, groundwater pumping regimes and irrigation water extraction from the river, and relates these targets directly to the maintenance of specific flora and faunal response targets (such as the maintenance of riparian vegetation or the protection of peak floods to ensure lateral connection to floodplains, ensure the maintenance of disturbance events for vegetation regeneration and the maintenance of breeding sites for pig-nosed turtles and fish. 
In the majority of cases, determining the safe range of change in the key groundwater attribute is difficult and time consuming. A priori considerations suggest that ecosystems may show a proportional (simple linear or a highly non-linear response function) response of ecosystem function to declining groundwater availability (hereafter called a degrading groundwater regime) or they may show a threshold response whereby minimal change occurs until a threshold of availability occurs. Whilst there are few empirical studies of this a priori view, there are several potential approaches to defining safe limits to changes in the groundwater regime. These include:

r) Examine long-term hydrological data from monitoring bores, along with long-term rainfall and vegetation survey data. Where vegetation survey data are absent, dendrochronological studies of tree rings and photographic records (Fensham 2003) may be useful. Long-term changes in average groundwater depth and rates of change and the duration of maxima and minima of groundwater depths are particularly important in these analyses. Froend and coworkers (Froend and Zencich 2001, Froend et al. 2004) have established such safe limits to changes in depth to groundwater through analyses of long-term vegetation surveys and groundwater data. These comparative data on mortality, species composition and groundwater depth before and after groundwater pumping, plus "control" sites where groundwater pumping has not occurred were used to identify three classes of phreatophytic vegetation and four classes of risk of impact of groundwater extraction as a function of rate of drawdown and the magnitude of drawdown (Froend and Loomes 2004).

s) Groundwater modelling can be used to calculate the response of groundwater level and groundwater pressure to a given rate of extraction, from which inferences can be made about likely vegetation responses using information from study like those described above. Froend et al. (2004) used modelled groundwater level change mapping to determine areas of phreatophytic vegetation susceptible to drawdown as a result of future groundwater resource development on the Swan Coastal Plain, WA. Similarly, models of aquifer-surface water interactions can be used to predict changes in stream-flow, from which inferences can be made about likely flora and faunal responses (Erskine et al. 2003). The most difficult task is formulating the inferences about vegetation responses to these changes in groundwater and stream hydrology. There is a paucity of data on ecosystem functional responses to changes in groundwater regime.

t) Multiple site comparisons within a single climate envelop, with sites chosen specifically to have known differences in groundwater regime can be used to derive correlations between ecosystem structure, function and groundwater regime. Loomes (2000) and Froend and 
Zencich. (2001) and O'Grady et al (2005) applied this approach to establish ecological water requirements of wetland species, Banksia woodlands and riparian vegetation.

u) A combination of detailed biological, hydrological and topographical knowledge is required to establish minimum groundwater regimes to maintain viable populations of key, iconic, keystone or threatened species. Three examples will suffice to show how such information can be synthesised to provide management goals. In the first, Georges et al (2002; cited in Erskine et al. 2003) determined the minimum dry season flow rates in the Daly River that are required to maintain viable populations of the pig-nosed turtle. By clearly identifying the breeding, feeding and range requirements of the pig-nosed turtle, plus the use of a onedimensional steady-state backwater model, HEC-RAS, breakpoints in the stream that would impede the movement and breeding of pig-nosed turtles were identified. From knowledge of the relationship between stream volume flow rate and stream topography, it was then possible to set a minimum dry season flow rate that would achieve a known rate of nesting along the river. In the second study, a similar approach was then used to determine flow-rate needed to maintain in-stream macrophyte populations. Preference curves for water depth, distance from river bank edge and mean and maximum flow velocities at 27 river channel cross-sections during the dry season were established for Vallisneria nana, an important species providing habitat for turtles and other vertebrates. V. nana occurred in the dry season within the depth range $0-1.3 \mathrm{~m}$ with a mean flow velocity range of $0-0.6 \mathrm{~m} \mathrm{~s}^{-1}$ and a maximum velocity within the range $0-0.75 \mathrm{~m} \mathrm{~s}^{-1}$. The probability of occurrence of dense beds of $V$. nana was maximal at depths of $0.6 \mathrm{~m}$ and at $5 \mathrm{~m}$ from the bank. Consequently, Georges et al. (2002, in Erskine et al 2003) were able to identify the range of flow regimes required to sustain these populations. By sustaining this keystone species, it is assumed that sufficient habitat will be maintained to ensure the full complement of other species will be similarly maintained. Finally, Begg et al. (2001, in Erskine et al. 2003) used a GIS to identify the extent and distribution of wetlands in the Daly River Basin. They then identified the threats to these from current and future rates of water use from the Daly River and provided an assessment of the risks and groundwater requirements for the maintenance of these wetlands. Ten different types of wetland were identified (river, creek, channel billabong, backflow billabong, floodplain billabong, floodplain, dampland, sumpland, waterhole and doline). The spatial extent of these was mapped on to 1:50,000 topographic maps based on the waterlogging characteristics of each land unit within the NT government land unit maps, plus the landform and water regime (permanently flooded, seasonally flooded or seasonally saturated). Threats were identified as agricultural and other land use practices, road and other construction and urban and mining development and water 
extraction from the river and groundwater sources. From these threats and land unit mapping, it was shown that different proportions of the different wetlands were likely to be affected by specific changes in land use. From this study, specific rules (such as no water extraction to occur on the rising stage and peak of flood hydrographs during the wet season; water extraction to a maximum of $20 \%$ of streamflow allowed when flood stage has dropped at least $1 \mathrm{~m}$ below peak values in the wet season;) about water extraction from the river were developed.

\subsection{What is the response function of species or ecosystems to a degraded groundwater regime?}

As previously discussed, a priori considerations suggest that vegetation may show a proportional or threshold response to a degrading groundwater regime. Field data to support this are difficult to obtain. Several approaches to this question can be taken. In the first, modelling of links between vegetation and groundwater at large-scales, with minimal attempt at resolution to species, can be attempted. Structural attributes are used (forest, woodland, grassland, for example) to describe ecosystems. Bauer et al. (2004) and Rains et al. (2004) take this approach (see below). A second approach uses attributes of individual plants and data are collected at the individual plant-scale, either for a dominant or group of dominant species. Scott et al. (1999) and Groom and Froend (see below) adopt this approach. The third approach is to look at ecosystem processes, such as nutrient cycling (Hefting et al. 2004; see below). Finally, a comparative approach looking at species diversity and community structure of sites differing in groundwater regime has been used (Brunke et al. 2003).

Bauer et al. (2004) used diurnal fluctuation in groundwater level in Botswana to estimate the contribution of groundwater to evapotranspiration by phreatic vegetation and were able to model the influence of local vegetation cover and soil characteristics. Presumably this approach could be reversed to infer vegetation change resulting from a change in groundwater availability, thereby establishing a vegetation response function to reduced groundwater availability. Similarly, Rains et al. (2004) developed a model linking groundwater and vegetation to simulate groundwater and vegetation distributions in a riverine and reservoir fringe community. Mean depth to groundwater was modelled for a 20 year period for each of 5 vegetation community types and multiple vegetation models were developed which generated a probability of occurrence for each of the vegetation types as a function of depth to groundwater and flooding. From this, changes in the distribution of each vegetation type were predicted under various hydrologic scenarios. Importantly, 
this approach was able to simulate multiple groundwater and surface water management regimes but also predict vegetation distributions in the riverine (riparian) and reservoir-fringe communities.

Scott et al. (1999) established transects across a river prior to mining activities which caused the depth of the water table to increase 1-2 m over a 2 y period. Tree survival, crown volume and stem increment of Populus forests in the USA all declined following the decline in water table. Similarly, increased mortality and changes in species composition have been observed in a 30 year study during which depth to groundwater increased, partly as a result of groundwater pumping and partly because of a significant decline in rainfall over the 30 year period (Groom et al. 2000b). Both studies highlight the value long-term vegetation surveys that start before pumping occurs and continue during the period of pumping. When a survey prior to pumping was not undertaken, a comparison with reference sites, where pumping is not occurring, must be used.

A threshold response does appear to be evident in both the Scott et al. (1999) study and the WA studies, although this could be a function of the vegetation parameters being studied. It is likely that a more proportional response would be observed if variables such as stomatal conductance and tree water use were measured rather than crown volume or mortality. Scott et al. (1999) identified branch diameter increment as being more sensitive to changes in groundwater regime than crown volume or survival and this showed a proportional response rather than a threshold response. Interestingly, branch growth is significantly correlated with stream volume flow (Willms et al. 1998), presumably because stream flow increases when groundwater depth decreases.

An alternative to looking at biotic (species or communities) responses to changes in groundwater availability, is to look at ecosystem processes. Hefting et al. (2004) examined the influence of water table depth on soil $\mathrm{N}$ cycling in riparian wetlands. Nitrification and denitrification are important factors influencing plant productivity and are aerobic processes, but nitrogen buffering capacity of soils is an anaerobic processes. They showed that depth to water table was a major determinant of soil $\mathrm{N}$ dynamics and observed three threshold responses. When the water table was close to the surface $(<10 \mathrm{~cm})$ ammonification was the main process and ammonium accumulated in the soil. When the water table was $>10<30 \mathrm{~cm}$ depth, denitrification was the dominant process and $\mathrm{N}$ was lost from the soil. When the water table was $>30 \mathrm{~cm}$ depth, nitrification dominated and soil $\mathrm{N}$ increased. Unfortunately, it is not immediately clear what the impact of these changes will be on vegetation structure, but the approach deserves further consideration. 
Brunke et al. (2003) examined the effect of the exchange between groundwater and surface water on the distribution of aquatic invertebrates within a riverine landscape in two floodplains pf a southern Alpine river. The two floodplains differed in hydrological regime. In the middle floodplain, lateral inputs and exfiltration of hillslope groundwater were important processes and bank infiltration of river water supported subsurface water for only a very short distance from the river bank. Aquatic habitats in this floodplain were relatively homogenous with high taxon richness and intra-habitat diversity. In the lower floodplain, groundwater and river water exchange was more extensive and aquatic floodplain habitats of this floodplain were mostly supplied by alluvial groundwater, hyporheic exfiltration and surface water. These floodplains showed low intra-habitat diversity and a high inter-habitat diversity were present. Interestingly, ordinations grouped the aquatic habitats according to the origin of the water and species turnover was related to differential lateral and vertical connectivity (Brunke et al. 2003). Consequently, changes in groundwater supply and interactions with surface waters results in changes in species composition, diversity and ecosystem structure. Such information is an important move towards being able to predict ecosystem response functions to changes in groundwater regime.

\subsection{What vegetation attributes can be measured to monitor ecosystem function?}

Having established the presence of a GDE and established a management target (for example maintaining groundwater depth within a certain range during the growing season), it is important to have a vegetation response that can be routinely measured and which will indicate that ecosystem function is being maintained. Developing a set of triggers which prompts management response to impacts, is a critical stage in the management process (Downes et al. 2002). A reference point, or particular value of an indicator is determined and deviance from this reference point determines management action (Jamieson et al. 2001). The importance of developing links between monitoring programs and management decision-making becomes evident as it is only through the reporting of monitoring outcomes (i.e. the deviation of an indicator from a reference point) that management action can be triggered (Finlayson and Eliot 2001; Morgan and Davis 1997). The response of management to a trigger being breached will vary depending on the nature of the breach and the management objectives. For example, EWPs may have to be adjusted if monitoring indicates the environmental condition of a GDE has declined to a level greater than is acceptable, or that a GDE appears to be more resilient than predicted (Sinclair Knight Merz 2001).

If we ignore the impacts of polluted groundwater, the impact of a degraded groundwater regime is essentially one of a (more or less) gradually increasing imposition of water (drought) stress. The 
response of native plants to drought stress follows a reasonably consistent pathway and therefore we can predict the cascade of responses (Fig. 1), from molecular to landscape responses, which occur over the time frame of days to decades (Smith and Griffiths 1993). It is not possible to review all the techniques that could be applied in assessing the performance of vegetation in response to a changing hydrologic balance. Pearcy et al. (1994) and Colvin et al. (2001) provide discussions of various methods that can be applied in the study of vegetation responses to drought.

There are several criteria required to decide which attributes to measure. These include:

- have a defined relationship with groundwater levels: there needs to be confidence that a measured response within a parameter reflects altered groundwater levels rather than other abiotic/biotic factors;

- characterise risk to the environment: parameters should identify, where possible, whether impacts to environmental values are short term or long term, reversible or irreversible and/or minor or major;

- are cost-effective and practical: parameters should be inexpensive enough to measure, although current monitoring practices may need to change to accommodate more appropriate additional or replacement parameters. Parameters that reflect landscape responses by GDEs of wide distribution, such as remote sensing of phreatophytic vegetation health, will be considered in light of the cost-effectiveness of such approaches;

- have early warning capabilities: the time from which a parameter indicates there is a potential change within a value, to the time that actual change occurs (lead-time), should be sufficient to provide the opportunity to implement appropriate management response.

Generally, the better the warning (the longer the period between potential change and actual change) the lower the accuracy of the parameter in portraying a response specific to a given stressor (i.e. depressed groundwater levels). A balance between these characteristics (leadtime and accuracy), should be considered to provide the most appropriate and cost-effective parameters. Further characteristics of early warning indicators and considerations which need to be taken into account when deciding on environmental, physical and/or chemical indicators are detailed in van Dam et al. (1998).

- consider the 'lag' effects between changed groundwater levels and environmental condition and/or health: response of parameters influenced by changed groundwater levels can take a long time and further reductions may occur before impacts of previous changes are 
realised. Consequently parameters with rapid responses are favoured, as they provide advanced warning of significant stress or degradation on the system, as well as providing the opportunity to determine whether intervention or further investigation is required (van Dam et al. 1998). However, some GDE values may have to be measured through parameters with a greater 'lag' time (e.g. phreatophytic vegetation community composition).

The ability to make predictions of the impact of a modified water regime on ecosystem components depends on an understanding of the relationship between the ecosystem component (e.g. wetland vegetation, phreatophytic vegetation, macroinvertebrates) and the water regime (Froend and Zencich 2001). Consideration needs to be made of this relationship at all ecological levels (community, population and individual), as all are linked: an individual species response has implications for population response which in-turn influences community composition or structure (Froend and Zencich 2001). Parameters that reflect condition and health of ecosystem components can be applied to all levels.

\subsection{Community Level Parameters}

GDE water regimes are reflected in vegetation as it provides numerous functions integral to the continued health of plants and the organisms they support (Loomes and Froend 2001b). Understanding the groundwater requirements of a plant community requires knowledge of community responses to short and long-term effects of groundwater fluctuation, groundwater abstraction and poor recharge events. Generally though, these responses are poorly understood (Froend and Zencich 2001). Regular monitoring of different plant communities along with the underlying hydrology is required before relationships between floristic structure and composition and groundwater regimes can be confidently described. Although more research is required to define groundwater-vegetation relationships and to improve the basis for decision making with regard to predicting the potential impacts of water regime modification on vegetation, Froend and Zencich (2001) provide details on specific parameters to measure, from which vegetation response to a given water regime can be correlated/associated (Froend and Zencich 2001).

Loomes and Froend (2001a) explain the distribution, growth and reproduction of wetland vegetation have strong relationships to depth, duration and amplitude of seasonal flooding, demonstrated by measuring the response of wetland vegetation to altered water regimes. As each species is adapted to specific water level ranges, changes may cause a shift in community 
composition and structure: lowering water tables can result in a loss of species intolerant of drying and their gradual replacement by terrestrial species. Detailed knowledge of the relationships between plant community composition and water regimes is still lacking (Loomes and Froend 2001a; Loomes and Froend 2001b), although a handful of studies have sought to address this issue (Froend et al. 1993; Groom et al. 2000; Loomes 2000). Loomes (2000) described the hydrology of 19 Swan Coastal Plain (SCP) wetlands in relation to the influence on composition and structure of wetland vegetation and grouped wetland vegetation species into hydrotypes, based on the water regimes they experienced, to predict the impact of altered hydrology on wetland vegetation composition and structure.

Overstorey species, where present, are generally used to define vegetation communities within wetlands and have many important ecological functions, making them suitable indicator species for monitoring wetland health. Overstorey species also tend to persist in highly disturbed plant communities when most other natives disappear (Pettit and Froend 2001), implying a greater lag response to changes in groundwater levels. As such, overstorey species are useful as long-term indicators of environmental condition and health.

Similarly, emergent macrophytes form dominant communities in wetlands and perform important ecological functions, also making them suitable indicators for monitoring wetland health. Emergent macrophytes are highly responsive to inter-annual variability in wetland surface levels and as such are well suited as short-term indicators, given their sensitivity to the early stages of a stressor (i.e. depressed groundwater levels).

As weed species are relatively quick to colonise disturbed areas, they may be useful as a short-term indicator of disturbance within GDE. For example, invasive exotic species such as Typha orientalis and annual exotic grasses can be measured as an indication of the level of disturbance within a wetland. This is important as high levels of weed invasion can have negative effects on species diversity and recruitment of native species. High levels of weed invasion within wetland vegetation are reflective of changes to community structure which in turn, may be a result of changes within the groundwater regime. 
Abundance (area), character (composition, floristic richness and structural diversity) and condition (collective vigour) of phreatophytic vegetation can be measured at a community level (Froend and Zencich 2001). Specifically, these parameters include:

\section{Abundance:}

- distribution (reduction/expansion) of a community along a water availability gradient may change in response to altered groundwater regimes. Alteration in the dominant species composition can be used as an indicator of change in community distribution.

\section{Character:}

- species diversity and composition in a community may change as species more vulnerable to prolonged dry periods become locally extinct and in severe cases diversity may be significantly reduced and comprise only xerophytic species;

- weed invasion may increase upon the death of drought intolerant species (Froend and Zencich 2002);

- structural changes, namely height structure, may occur in a community as mature trees senesce as a result of altered groundwater regime (Froend and Zencich 2002).

\section{Condition:}

- regeneration index over time (divide number of seedlings in the plot by the number of trees plus one, in the plot, to give an indication of persistence of GDE vegetation at a site);

- canopy fullness/density of indicator species (e.g. overstorey species) to give an indication of the health of GDE vegetation;

\subsection{Population level parameters: Indicator species}

Population dynamics of appropriate indicator species can be used to reflect the health and condition of GDE vegetation. A subset of plants within a GDE can be used as indicators e.g. dominant overstorey species (Pettit and Froend 2001). Overstorey species have many important ecological functions within plant communities and as such are suitable indicators for monitoring wetland health (Pettit 1997). Given the relatively long 'lag' response of overstorey species to changes in groundwater levels, they are useful indicators of environmental condition and health over the longterm. 
An example is the drought sensitive Holly-leaf Banksia (Banksia ilicifolia), which has been identified as an important indicator of long and short term changes in groundwater levels on the Gnangara mound and on other shallow aquifers on the Swan Coastal Plain, as groundwater drawdown has a documented negative impact of population size and vigour of this species (Groom et al. 2001). B. ilicifolia is useful as a key indicator species as it is an overstorey species, easy to record and identify, and generally used to define vegetation communities.

Abundance, character and condition of species response to water regimes can also be measured at a population level to describe response to water regime (Froend and Zencich 2002):

\section{Abundance:}

- size of a local population is a measure of species persistence and resilience. Recruitment potential can be determined by the size and distribution of mature individuals and is also affected by density. Higher density stands of a species require greater water availability;

- distribution of a population along a water availability gradient reflects the water requirements of a species and changes in water regime that exceed the tolerance limits of individuals may lead to a gradual change in species distribution. Distribution of indicator plant species along a gradient can be used to give an indication of the groundwater availability gradient as specific species are associated with specific depth to groundwater ranges.

\section{Character:}

- size (height) and age structure of population can be measured to give an indication of drawdown effects. Populations affected by drawdown may demonstrate a lack of recruitment as water availability is insufficient to support successful establishment, and are characterised by few, mature individuals and no new recruits. In contrast, dynamic, resilient populations are characterised by many cohorts of different ages, particularly young individuals. Froend and Zencich (2002) note an exception however, when mature plants succumb to drawdown events, leaving only younger members of the population, tolerant of the 'new' water regime;

- longevity (and therefore persistence) and resilience of a local population may be significantly impacted by groundwater drawdown that exceeds the tolerance limits of the population.

\section{Condition:}

- population vigour, or the appearance of a species, can be assessed using indices of canopy vigour (e.g. canopy condition index (fullness/density, presence/absence of dead braches and 
epicormic growth), leaf area index (LAI). Other population measures of vigour include incidence of juvenile, mature, reproductive, flowering and senescent individuals ;

- regeneration potential is also reflective of condition or vigour of a population. Lack of regeneration potential (lack of seedlings, no juveniles or saplings, only senescent trees present) represents a loss of vigour. However, to use regeneration potential as a measure of drawdown impact requires other factors such as grazing or fire management to be ruled out. Parameters used to measure regeneration potential include lack of regeneration, recruitment rate, seedling survivorship and seed bank viability.

\subsection{Individual level parameters}

Individual plant response to water regimes can only be measured and quantified in terms of condition. As such, ecophysiological techniques that directly reflect the vigour of a plant are used when measuring the condition of individuals (Froend and Zencich 2002). These include (Table 2):

- measurement of plant water relations via pre-dawn water potentials and gas exchange. These parameters reflect plant response over time to water availability, although only provide an indication of potential water source use;

- measurement of water flux via sap flow techniques,. This provides information on the rates and timing of consumptive use by a species. Can also be used to assess changes in water use when water availability changes

- measurement of water sources used via isotopic tracers. This allows water sources accessed by plants to be identified and the contributions of potential water sources to be recognised. This knowledge is critical for estimating and modelling community-scale water balance.

The above parameters provide a more defined relationship between groundwater levels and the condition of phreatophytic vegetation than community and population level parameters, however they are quite labour intensive and costly but can (depending on sampling frequency) have a very short lag time and therefore have efficient early warning capabilities. 


\subsection{Environmental variables}

When monitoring vegetation it is important to measure environmental variables that will influence vegetation communities, while which environmental variables to measure will in part depend on the objectives of the monitoring program. Variables relevant to assessing the response of vegetation to altered groundwater levels are:

- groundwater levels and fluctuating water regimes (duration of wet/dry phases, seasonality);

- water quality (nutrient concentrations, salinity, toxicants);

- soil water retention capacity and soil stratigraphy (water retention layers above water table);

- climatic information (rainfall and maximum temperatures during summer/early autumn) can be useful in determining the cause of changes to vegetation;

- records of past fires (as this may have strong impact on composition of vegetation and can compound effects of other environmental factors, such as water regime, on wetland vegetation 


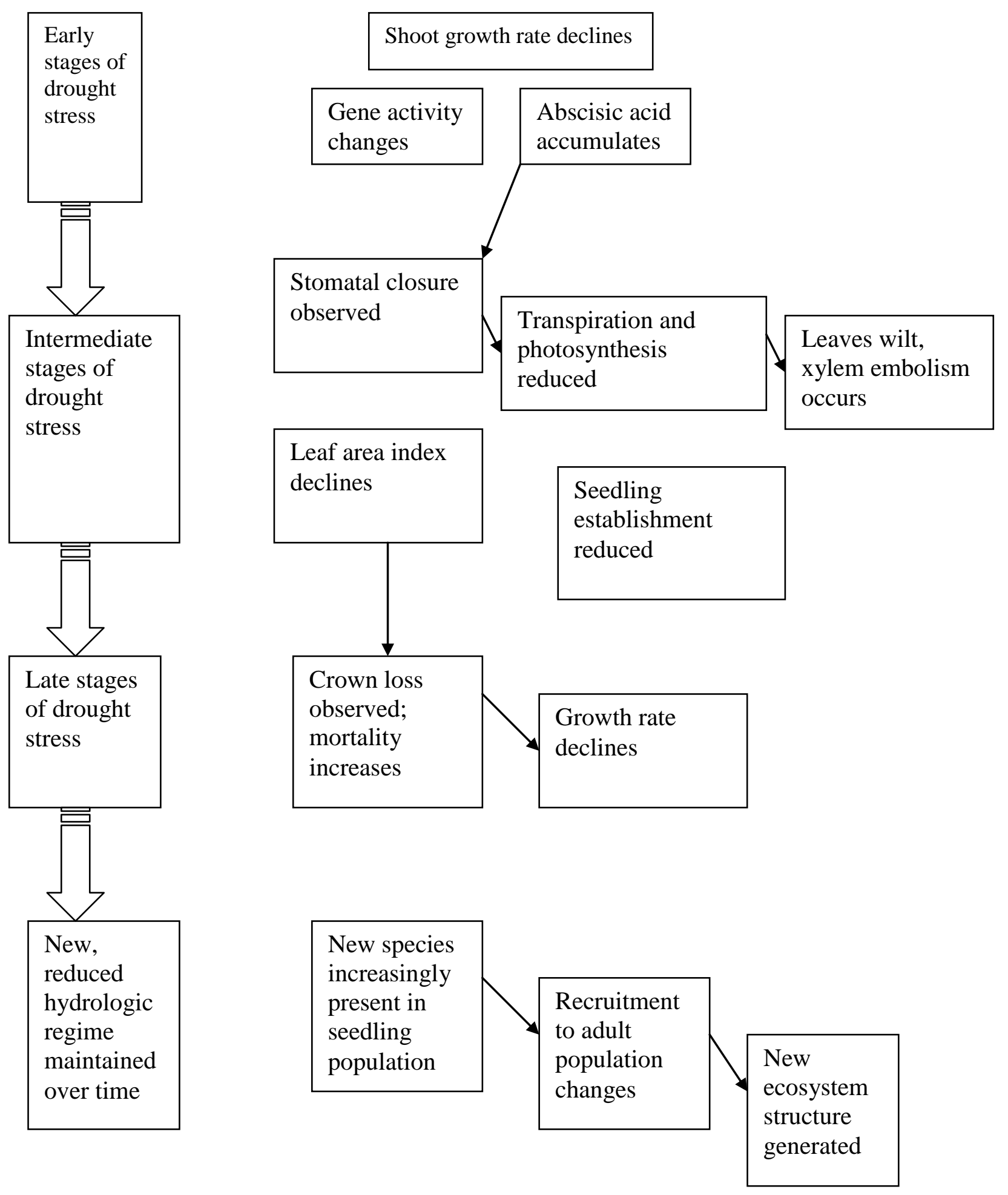

Figure 1. Short, medium and longer-term changes in ecosystem function can be monitored at a range of scales. 


\subsection{Concluding comments: putting it into practice}

The Council of Australian Governments (COAG) endorsed water resource management reforms in 1994 to achieve a sustainable water industry that included allocations for the environment and greater environmental accountability of water resource developments. The National Principles for the Provision of Water for Ecosystems produced by the Agricultural and Resource Management council of Australia and New Zealand (ARMCANZ) and Conservation Council (ANZECC) provided the basis for considering ecological water requirements (EWRs) as part of water allocation decisions by water resource managers.

In response to the COAG and ARMCANZ/ANZECC agreements a variety of approaches have been developed nationally to determine the water requirements of dependent ecosystems. The majority of these however, have focussed on the requirements of ecosystems dominated by surface water flows with fewer approaches directed entirely towards groundwater dependent ecosystems. Research and water resource planning in Western Australia during the last decade (reviewed in Froend et al. 2004) has identified several issues relevant to a functional approach to determining ecosystem groundwater requirements:

- There needs to be acknowledgement of variability in groundwater dependency within a GDE; e.g. variability in groundwater dependency of phreatophytic vegetation relative to depth the water table and hydrological ranges (tolerances) of wetland vegetation. Failure to do so leads to insufficient awareness of biological/ecological variability and incorrect interpretation of EWRs as absolute 'thresholds' of tolerance.

- Simplification of water requirements into minimum water table depths without recognition of other hydrological variables important to the ecology of the system can lead to an underestimation of water requirements; e.g. duration, timing and rate of seasonal flooding/drying and the episodicity of extreme flooding/drying events need to be considered in a addition to just groundwater level.

- The lag-response in the ecology should be considered particularly where GDE have a history of progressive decline in water tables. The cumulative effects of reduced groundwater availability are important.

- The resilience of GDEs to drawdown impacts should also be considered. Ecosystems impacted by change in groundwater availability may recover to an acceptable condition. 
- Consideration should be given to GDEs as part of a system/catchment approach towards identifying water requirements and possible impacts.

- Application of a risk (of impact) assessment incorporating variability in current vulnerabilities (water requirements and drought stress) and potential degree of change/impact.

- Management (environmental compliance) criteria based on simplified minimum 'threshold' water table levels without consideration of acceptable changes to ecological values.

- Inaccurate assessment of groundwater levels/wetland surface water level relative to GDE ecology; e.g. no groundwater monitoring at vegetation monitoring sites.

Failure to address these issues has often led to the identification of water requirements that do not accurately reflect the requirements of the ecology, often resulting in regulatory breaches of environmental conditions (without obvious ecological impact) or understated water requirements leading to unexpected environmental impacts.

Table 2. A range of techniques are available to measure aspects of ecosystem function that might be expected to respond to a change in hydrologic regime. Control (reference) sites greatly improve the power of the measurements. These should be close to the experimental sites with the same species and soil types present as at the experimental site.

\begin{tabular}{|l|l|l|l|}
\hline \multicolumn{1}{|c|}{ Measurement } & \multicolumn{1}{|c|}{ Technique } & \multicolumn{1}{c|}{ Commentary } & \multicolumn{1}{c|}{ Reference } \\
\hline Leaf water potential & Pressure bomb & $\begin{array}{l}\text { Simple, cheap, but a nearby reference } \\
\text { (control) site is required because it } \\
\text { responds to climate (rainfall; } \\
\text { temperature, solar radiation, VPD) } \\
\text { rapidly. Access to canopy for leaves } \\
\text { can be difficult }\end{array}$ & Myers et al. \\
\hline Stomatal & ponductance & $\begin{array}{l}\text { Simple, cheap, rapid, but a nearby } \\
\text { reference (control) site is required } \\
\text { because it responds to climate } \\
\text { (rainfall; temperature, solar radiation, } \\
\text { VPD) rapidly. Access to canopy for } \\
\text { leaves can be difficult }\end{array}$ & Eamus et al. \\
& & &
\end{tabular}




\begin{tabular}{|c|c|c|c|}
\hline $\begin{array}{l}\text { Transpiration }- \text { tree } \\
\text { or canopy scale }\end{array}$ & $\begin{array}{l}\text { Sapflow sensors } \\
\text { for trees; eddy } \\
\text { covariance or } \\
\text { Bowen ratio for } \\
\text { canopies }\end{array}$ & $\begin{array}{l}\text { Technically difficult and time- } \\
\text { consuming; not cheap. A nearby } \\
\text { reference (control) site is required } \\
\text { because it responds to climate } \\
\text { (rainfall; temperature, solar radiation, } \\
\text { VPD) rapidly. }\end{array}$ & Zeppel et al. \\
\hline $\begin{array}{l}\text { Leaf area index; } \\
\text { canopy fullness; } \\
\text { crown health }\end{array}$ & $\begin{array}{l}\text { Visual assessment; } \\
\text { hemispherical } \\
\text { photographs; LAI } \\
\text { analyser, or remote } \\
\text { sensing }\end{array}$ & $\begin{array}{l}\text { Visual assessment easy, rapid and } \\
\text { cheap. LAI responds seasonally. } \\
\text { Hemispherical photographs } \\
\text { technically difficult to analyse. LAI } \\
\text { analyser not suitable for all vegetation } \\
\text { structures. Remote sensing } \\
\text { increasingly available but expensive } \\
\text { and not available for all sites and best } \\
\text { suited to long-term }(2+\text { y) studies. }\end{array}$ & $\begin{array}{l}\text { O'Grady et } \\
\text { al. }\end{array}$ \\
\hline Growth rate & $\begin{array}{l}\text { Band } \\
\text { dendrometers }\end{array}$ & $\begin{array}{l}\text { Simple, cheap and can be left in the } \\
\text { field for years. }\end{array}$ & Prior et al. \\
\hline $\begin{array}{l}\text { Seedling } \\
\text { establishment }\end{array}$ & $\begin{array}{l}\text { Fixed plots } \\
\text { measured over } \\
\text { time }\end{array}$ & & \\
\hline $\begin{array}{l}\text { Cover and } \\
\text { abundance of } \\
\text { indicator plant } \\
\text { species }\end{array}$ & $\begin{array}{l}\text { Fixed plots } \\
\text { measured over } \\
\text { time. }\end{array}$ & $\begin{array}{l}\text { Valuable quantitative assessment of } \\
\text { population and (indicated) community } \\
\text { response over the long-term }(3+y) \text {. } \\
\text { Simple and relatively cheap. Used as } \\
\text { ground truthing for remote sensing. }\end{array}$ & $\begin{array}{l}\text { Froend and } \\
\text { coworkers }\end{array}$ \\
\hline $\begin{array}{l}\text { Community } \\
\text { distribution/zonation } \\
\text { change }\end{array}$ & $\begin{array}{l}\text { Visual assessment } \\
\text { in fixed plots } \\
\text { measured over } \\
\text { time }\end{array}$ & $\begin{array}{l}\text { Simple and relatively cheap. Provides } \\
\text { a measure of community response to } \\
\text { shifting water availability gradient. } \\
\text { Most often applied where distinctive } \\
\text { gradients in groundwater use are } \\
\text { evident, e.g. wetland fringes. Requires } \\
\text { repeated measures over the long-term } \\
(3+y)\end{array}$ & $\begin{array}{l}\text { Froend and } \\
\text { Loomes }\end{array}$ \\
\hline
\end{tabular}




\subsection{References}

Amlin MN, Rood BS (2002) Comparative Tolerances of Riparian Willows and Cottonwoods to Water-Table Decline. Wetlands 22, 338-346.

Anon (2000) 'Global Trends 2015.' Office of the National Intelligence Council, Washington, USA.

Arthington AH, Zalucki JM (1998) Water for the Environment: Recent approaches to assessing and providing environmental flows. In 'Conference proceedings of the Australian Water and Wastewater Association Interest Group on Catchment and Water Resource Management'

Bauer P, Thabeng G, Stauffer F, Kinzelbach W (2004) Estimation of the evapotranspiration rate from diurnal groundwater level fluctuations in the Okavango Delta, Botswana. Journal of Hydrology 288, 344-355.

Begg, GW, van Dam, RA, Lowry, JB, FInlayson, CM, and Walden DJ. 2001. Inventory and risk assessment of water dependent ecosystems in the Daly Basin, NT, Australia. Supervising Scientist Report 162. Darwin, NT, Australia.

Brunke M, Hoehn E, Gonser T (2003) Patchiness of River -Groundwater Interactions within Two Floodplain Landscapes and Diversity of aquatic invertebrate communities. Ecosystems 6, 707-722.

Caldwell M, Dawson T, Richards J (1998) Hydraulic lift: Consequences of water efflux from the roots of plants. Oecologia 113 (2), 151-161.

Colvin C, le Maitre D, Hughes S (2001) Assessing vegetation ecosystem dependence on groundwater.

Cook, PG, Favreau, G., Dighton, JC, and Tickell S (2003) Determining natural groundwater influx to a tropical river using radon, chlorofluorocarbons andionic environmental tracers. Journal of Hydrology 277, 74-88.

Cook P, Hatton T, Pidsley DH, Held A, O`Grady A, Eamus D (1998) Water balance of a tropical woodland ecosystem, northern Australia: a combination of micrometeorological, soil physical and groundwater chemical approaches. Journal of Hydrology 210, 167-177.

Costanza R, d'Arge, R, de Groot, R, Farber, S, Grasso, M, Hannon, B, Limburg, K, Naeem, S, O'Neill, R, Paruelo, J, Raskin, R, Sutton, P and van den Belt, M (1997) The value of the world's ecosystem services and natural capital. Nature 387, 253-260.

Downes, B., Barmuta, L., Fairweather, P., Faith, D., Keough, M., Lke, P., Mapstone, B., \& Quinn, G., Ed. (2002). Monitoring Ecological Impacts: Concepts and practice in flowing waters.

Cambridge, Cambridge University Press.

Eamus D, Macinnis-Ng C, Hose GC, Zeppel M, Taylor D, Murray BR Ecosystem services: an ecophysiological examination. Australian Journal of Botany 53, 1-37.

Erskine, W,D., Begg, G.W., Georges, Eamus, D., Rea, N., Townsend, S., Webster, I., Larson, H.. 2003. Recommended Environmental Water Requirements based on Ecological Hydrological and Biological Principles for the Daly River, NT. Office of the Supervising Scientist, NT. 58 pp. 
Fensham, R.J and Fairfax, R.J. (2003). Assessing woody vegetation cover change in north-west Australian savanna using aerial photography. International Journal of Wildland Fire 12, 359-367.

Finlayson, C. M., \& Eliot, I. (2001). Ecological Assessment and Monitoring of Coastal Wetlands in Australia's Wet-Dry Tropics: A Paradigm for Elsewhere? Coastal Management, 29, 105-115.

Froend, R. H., Farrell, R.C., Wilkins, C.F., Wilson, C.C., \& McComb, A.J. (1993). Wetlands of the Swan Coastal Plain (Volume 4): The Effect of Altered Water Regimes on Wetland Plants. Water Authority of Western Australia \& Environmental Protection Authority, Perth, Western Australia

Froend, R. and Zencich, S. (2001). PhreatophyticVegetation and Groundwater Study. Phase 1: Phreatophytic Vegetation Research Review. A report to the Water Corporation. Centre for Ecosystem Management, ECU, Joondalup.

Froend, R., Loomes, R., Horwitz, P., Bertuch, M., Storey, A. and Bamford, M. (2004). Study of Ecological Water Requirements on the Gnangara and Jandakot Mounds under Section 46 of the Environmental Protection Act. Task 2: Determination of Ecological Water Requirements. A report to the Water and Rivers Commission. Centre for Ecosystem Management, ECU, Joondalup.

Froend RH, Loomes WJ (2004) 'Approach to determine ecological water requirements of groundwater dependent ecosystems in WA.' Report to the Water and Rivers Commission, WA.

Froend RH, McComb AJ (1994) Distribution, productivity and reproductive phenology of emergent macrophytes in relation to water regimes at wetlands of south-western Australia. Australian Journal of Marine and Freshwater Research 45, 1491-1508.

Groom PK, Froend RH., Mattiske EM (2000a) Impact of groundwater abstraction on a Banksia woodland, Swan Coastal Plain, Western Australia. Ecological Management \& Restoration 1, 117124.

Groom PK, Froend RH, Mattiske EM, Gurner RP (2001) Long-term changes in vigour and distribution of Banksia and Melaleuca overstorey species on the Swan Coastal Plain. Journal of the Royal Society of Western Australia 84, 63-69.

Groom PK, Froend RH, Mattiske EM, Koch B (2000b) Myrtaceous shrub species respond to longterm decreasing groundwater levels on the Gnangara Groundwater Mound, northern Swan Coastal Plain. Journal of the Royal Society of Western Australia 83, 75-82.

Groot R, Wilson M, Boumans R (2002) A typology for the classification, description and valuation of ecosystem functions, goods and services. Ecological Economics 41, 393-408.

Hatton TJ, Evans R (1997) 'Dependence of Ecosystems on Groundwater and its significance to Australia.' Land \& Water Resources Research and Development Corporation, Canberra, Aust.

Hefting M, Clement JC, Dowrick D, Cosandey AC, Bernal S, Cimpian C, Tatur A, Burt TP, Pinay G (2004) Water table elevation controls on soil nitrogen cycling in riparian wetlands along a European climatic gradient. Biogeochemistry 67 (1): 113-134.

Hughes F, Rood S (2003) Allocation of River Flows for Restoration of Floodplain Forest Ecosystems: A Review of Approaches and their applicability in Europe. Environmental Management 32, 12-33.

Humphreys WF (2005) Groundwater ecosystems. Australian Journal of Botany this volume. 
Jamieson, G., \& O'Boyle, R. (2001). Proceedings of the National Workshop on Objectives and Indicators for Ecosystem-based Management. Sidney, British Columbia, Fisheries and Oceans Science and Canadian Science Advisory Secretariat.

Kingsford, RT (2002) Ecological impacts of dams, water diversions and river management on floodplain wetlands in Australia. Austral Ecology 25, 109-127,

Loomes RC (2000) Identification of wetland plant hydrotypes on the Swan Coastal Plain WA. PhD thesis, Edith Cowan University.

Loomes, R. C., \& Froend, R.H. (2001a). Gnangara Mound Groundwater Resources Section 46 Vegetation Condition Assessment. A report to the Water and Rivers Commission. Centre for Ecosystem Management Report No. 2001-14, ECU, Joondalup.

Loomes, R. C., \& Froend, R.H. (2001b). Review of Interim Wetland Vegetation Water Level Criteria - East Gnangara Wetlands. A report to the Water and Rivers Commission of Western Australia. Centre for Ecosystem Management, Edith Cowan University, Perth.

Morgan, D., \& Davis, J. (1997). Physico-Chemistry. In D. Morgan (Ed.). A Review of Wetland Monitoring with Particular Reference to Swan Coastal Plain Wetlands. Perth, Western Australia, Edith Cowan University.

Murray B, Zeppel M, Hose G, Eamus D (2003) Groundwater-dependent ecosystems in Australia: Its more than just water for rivers. Ecological Management and Restoration 4, 110-113.

Murray BR, Hose GC, Eamus D (2005) Ecosystem services and the valuation of groundwater dependent ecosystems. Australian Journal of Botany. This volume.

O'Grady, AP, Eamus, D., Cook, PG and Lamontagne S (2005). Groundwater use by riparian vegetation along the Daly River in the wet-dry tropics of northern Australia - A study of sapflow and stable isotoped. Australian Journal of Botany. This edition.

Pearcy R, Ehleringer JR, Mooney H, Rundel P (Eds) (1994) 'Plant Physiological Ecology.' Chapman and Hall, UK.

Pettit NE, and Froend RH (2001) Availability of seed for recruitment of riparian vegetation: a comparison of a tropical and temperate river ecosystem in Australia. Australian Journal of Botany 49, 515-528.

Pettit N, Froend R, Davies P (2001) Identifying the natural flow regime and the relationship with riparian vegetation for two contrasting western Australian rivers. Regulated Rivers - Research and Management 17(3), 201-215.

Rains MC, Mount, JE and Larsen, EW. (2004) Simulated changes in shallow groundwater and vegetation distributions under different reservoir operations scenarios. Ecological applications 14, 192-207.

Roberts J, Young W, Marston F (2000) 'Estimating the water requirements for plants of Floodplain wetlands. A guide.' CSIRO Land and Water Consultancy Report, 99/60.

Rood SB, Braatne JH, Hughes FMR (2003) Ecophysiology of riparian cottonwoods: stream flow dependency, water relations and restoration. Tree Physiology 23: 1113-1124. 
Scott ML, Shafroth PB, Auble GT (1999) Responses of riparian cottonwoods to alluvial water table declines. Environmental Management 23, 347-358.

Shafroth P, Auble G, Stromberg J, Patten D (1998) Establishment of woody riparian vegetation in relation to annual patterns of streamflow, Bill Williams River, Arizona. Wetlands 18(4), 577-590.

Shafroth P, Stromberg J, Patten D (2002) Riparian vegetation response to altered disturbance and stress regimes. Ecological Applications 12, 107-123.

Sinclair Knight Merz. (2001). Environmental Water Requirements of Groundwater Dependent Ecosystems. Environmental Flows Initiative Technical Report No. 2. Canberra, Commonwealth of Australia.

Smith J, Griffiths H (Eds) (1993) 'Water Deficits Plant responses from cell to community.' Environmental Plant Biology (BIOS Scientific Publishers)

Thorburn P, Hatton T, GR W (1993) Combining measurements of transpiration and stable isotopes to determine groundwater discharge from forests. Journal of Hydrology 150, 563-587.

van Dam, R. A., Camilleri, C., \& Finlayson, C.M. (1998). The Potential of Rapid Assessment Techniques as Early Warning Indicators of Wetland Degradation: A Review. Environmental Toxicology and Water Quality, 13, 297-312.

Willms J, Rood SB, Willms W, Tyree M (1998) Branch growth of riparian cottonwoods: a hydrologically sensitive dendrochronological tool. Trees - Structure and Function 12: 215-223

Zencich S, Froend RH, Turner J, V G (2001) Influence of groundwater depth on the seasonal sources of water accessed by Banksia tree species on a shallow, sandy coastal aquifer. Oecologia 131, 8-19. 
Table 1. A summary of the key questions to be addressed and methods that may be applied in the process of identifying and managing groundwater dependent ecosystems. Not all of these are discussed in this paper.

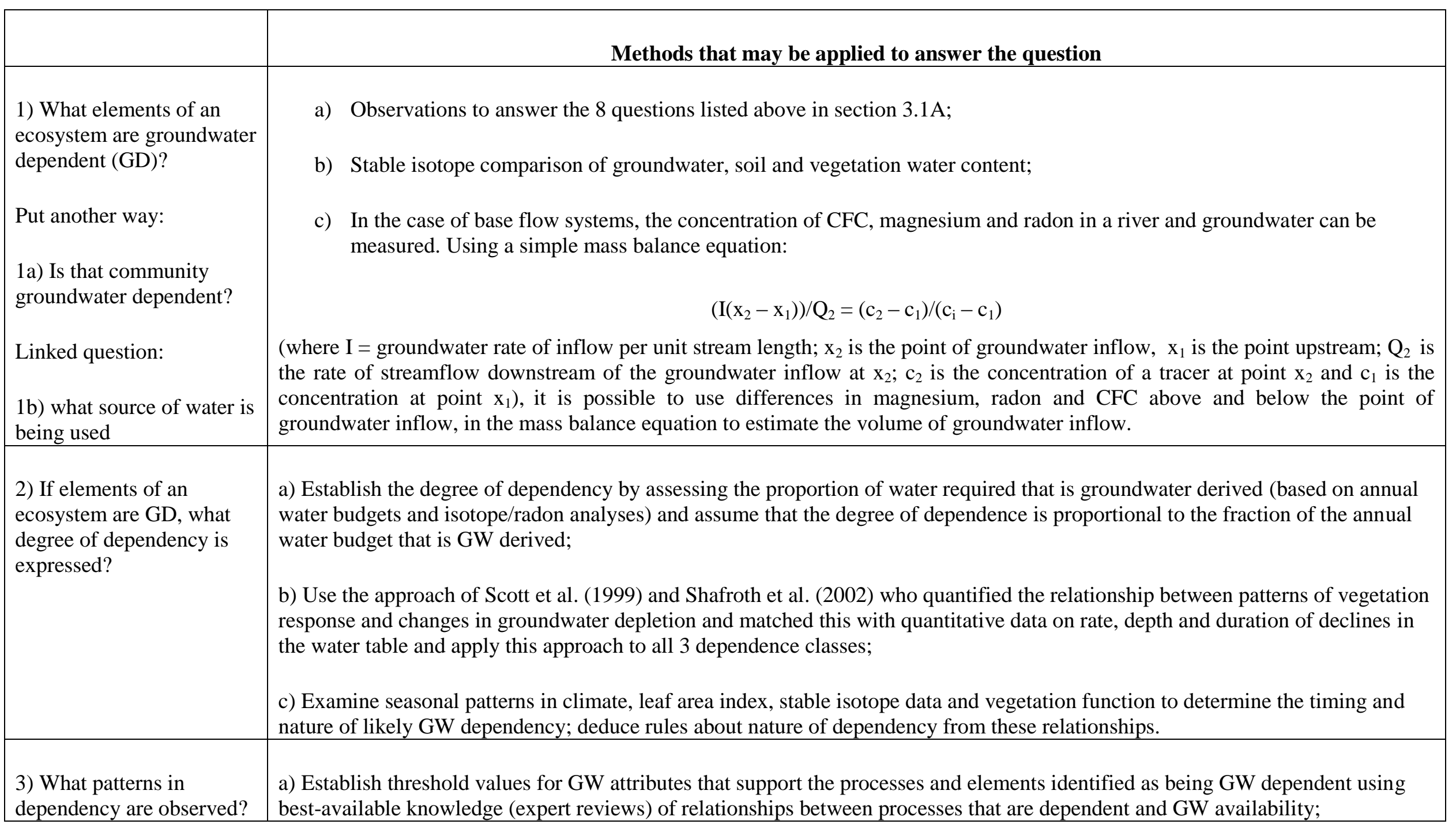


b) Establish consumptive rates of GW use, where appropriate;

c) Establish temporal and spatial distribution of GW use and availability;

4) What processes are $\mathrm{GW}$ dependent? a) For wetlands, for example, examine relationships among timing of seasonal flooding, climate and key ecosystem processes, especially growth rate, flowering, seed germination and dispersal.

b) For wetlands, for example, examine the long-term records for frequency, duration and depth of flooding and population demography, thereby establishing a link between the important components of the water regime and recruitment and population structure.

c) For wetlands, for example, examine the relationships among tolerance to flooding of key species, the historical record of floods and zonation of species distribution.

d) Similar relationships can be examined for terrestrial and baseflow systems too.

5) What attributes of GW (level, flux, pressure, quality) are important to the dependent elements?

6) What are the safe limits to changes in the attributes of GW that are important? a) Establish benchmarking (or reference condition) for comparable systems in comparable climate envelopes where GW abstraction or availability have not changed and compare vegetation/ecosystem responses;

b) Interrogate data from long-term monitoring sites (where available), and where not available, establish expert assessment of the likely impacts of changes in flux, level, quality or pressure on GW dependent systems;

c) Apply the approach of Loomes (2000), who analysed the distribution of 60 wetland species in relation to surface water data to determine mean minimum and maximum water depths to establish EWRs, to the other classes of ground water dependent systems (phreatophytic and baseflow), by comparing sites with known differences in GW attributes (level, flux etc).

a) Compare and contrast the community composition, structure and functioning of groundwater dependent communities having different groundwater availabilities, within each class of groundwater dependent ecosystem (ie, within the three classes: wetlands, baseflow systems and phreatophytic systems).

b) Apply the methodology and results of Loomes (2000), who analysed the distribution of 60 wetland species in relation to surface water data to determine mean minimum and maximum water depths to establish EWRs, to the other classes of ground water dependent systems (phreatophytic and baseflow), by comparing sites with known differences in GW attributes (level, flux etc); 
c) Examine which ecosystem process (eg consumptive water use by trees; or germination and recruitment of seeds/seedlings) is most dependent on GW and thereby infer safe limits of GW change. For example, if different vegetation habits (tree water use versus shrub water use, for example) have different dependencies (as found by Froend and co-workers in WA) then safe limits for changes in GW depth can be determined for a site using this information;

d) Establish rooting depths of GD systems and seasonal patterns of depth to watertable.

e) Compare the response of hyporheic invertebrate communities in baseflow systems to changes in flow permanence and timing. Consider the significance of the loss of habitat distinction (eg surface riffles and pools) if baseflows are limited to the hyporheic zone.

f) Assess the likelihood of baseflow dependence by analysis of low flow stream signatures, hydrographic baseflow separation techniques, isotopic analysis and partitioning of water sources, and calibration of local stream-aquifer interaction models.

g) Use Hotspots software to calculate how much GW can be extracted before GW pressure/level are adversely affected and to model stream-aquifer interactions.

7) What is the response function of key species or the community to changes in GW regime (supply/flux/pressure/quali ty or level)?

8) What values are assigned by all stakeholders, to the GD elements of the ecosystem?

9) What are the acceptable a) Compare and contrast the community composition, structure and functioning of groundwater dependent communities having different groundwater availabilities, within each class of groundwater dependent ecosystem (ie, within the three classes: wetlands, baseflow systems and phreatophytic systems);

b) Establish the ranking of change in cover, recruitment, growth rate or other attribute of individual species' health to changes in water regime, within each of the 3 classes of dependent systems;

c) Examine relationships between net primary productivity and water availability of a large number of diverse sites to establish the response function of NPP to changes in water availability.

a) Community consultation on all values assigned to the system showing GW dependency;

b) Expert assessment of biodiversity/rare and endangered species, uniqueness and other values of the ecosystem;

c) Economic assessment of ecosystem services, including amenity, tourism, conservation, economic productivity (eg pastoral use).

a) Community consultation on defining the acceptable limits of change in system values, identified from (8) above; 


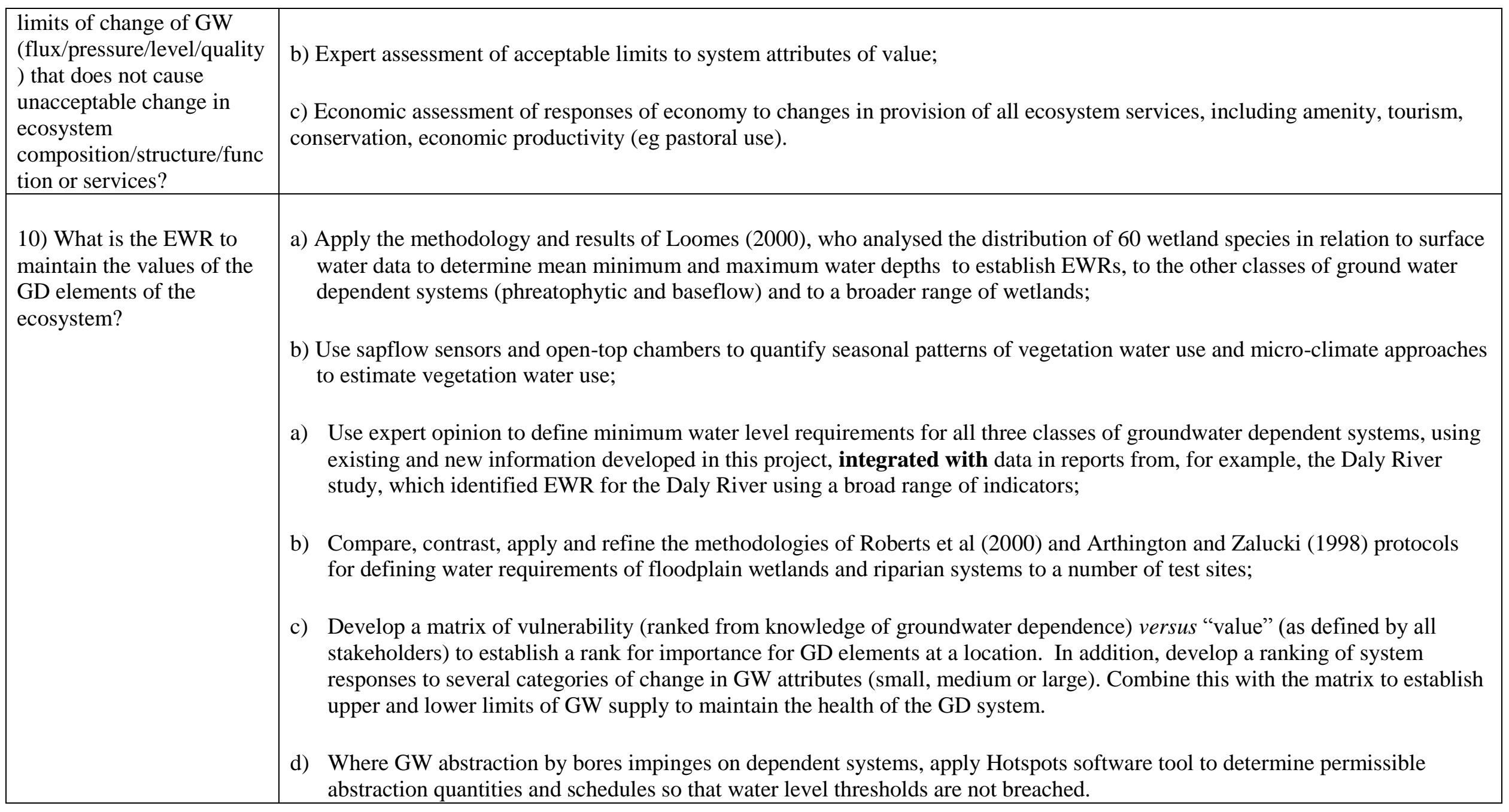

